\title{
Prevalence and Mechanism of Antimicrobial Resistance in Staphylococcus aureus Isolates from Diseased Cattle, Swine and Chickens in Japan
}

\author{
Kotaro BABA ${ }^{1)}$, Kanako ISHIHARA ${ }^{2)}$, Manao OZAWA ${ }^{1)}$, Masaru USUI ${ }^{1)}$, Mototaka HIKI), Yutaka TAMURA ${ }^{2)}$ and \\ Tetsuo ASAI ${ }^{1) *}$ \\ 1) National Veterinary Assay Laboratory, Ministry of Agriculture, Forestry and Fisheries, 1-15-1 Tokura, Kokubunji, Tokyo \\ 185-8511, Japan \\ 2) Food Microbiology and Food Safety, Department of Health and Environmental Sciences, School of Veterinary Medicine, Rakuno \\ Gakuen University, Midorimachi, Bunkyodai, Ebetsu, Hokkaido 069-8501, Japan
}

(Received 28 July 2011/Accepted 26 November 2011/Published online in J-STAGE 9 December 2011)

ABSTRACT. Antimicrobial administration is essential for the control and treatment of diseases in animals, but the emergence and prevalence of antimicrobial-resistant Staphylococcus aureus is a significant concern during animal production. Here we investigated the antimicrobial susceptibility of $S$. aureus from diseased food-producing animals and molecularly characterized the methicillin-resistant and fluoroquinolone-resistant isolates. A total of $290 \mathrm{~S}$. aureus isolates obtained from cattle $(\mathrm{n}=246)$, swine $(\mathrm{n}=16)$, and chickens $(n=28)$ between 2003 and 2009 were examined for antimicrobial susceptibility against 9 antimicrobials using an agar dilution method. Resistance to penicillin (PC) was most frequently found (24.8\%), followed by oxytetracycline (OTC, 10.0\%), dihydrostreptomycin (4.1\%), erythromycin (EM, 3.1\%), enrofloxacin (ERFX, 2.1\%), and kanamycin (1.7\%). The PC resistance rate was significantly higher in swine than in cattle $(P<0.01)$ and chickens $(P<0.01)$. The resistance rates to OTC, EM and ERFX were significantly higher in swine and chickens than in cattle $(P<0.05)$. Methicillin-resistant $S$. aureus (MRSA) was recovered from milk derived from a cow with mastitis in 2003; sequence type 8, SCCmec type IV and spa type t024. In the six ERFX-resistant strains isolated after 2003, amino acid substitutions in ParC with/without GyrA were detected. As the prevalence of MRSA and FQ-resistant $S$. aureus in the animals should be noticed, continuous monitoring is necessary to control resistance to clinically important antimicrobials in $S$. aureus from food-producing animals.

KEY WORDS: antimicrobial susceptibility, enrofloxacin resistance, food-producing animals, methicillin resistance, Staphylococcus aureus.

doi: 10.1292/jvms.11-0357; J. Vet. Med. Sci. 74(5): 561-565, 2012

Staphylococcus aureus causes a variety of inflammatory diseases in domestic animals; e.g. mastitis in dairy herds [3], exudative dermatitis in pigs [26], and osteomyelitis and arthritis in poultry [23]. The diseases caused by $S$. aureus are often connected to severe economic losses in animal industries. As antimicrobial administration is essential for the control and treatment of these diseases in animals, the emergence and prevalence of antimicrobial-resistant $S$. aureus is a significant concern in animal production. It is important to provide information on antimicrobial susceptibility of $S$. aureus isolates from foodproducing animals for animal practitioners.

Bacteria of food animal origin showing resistance to clinically important antimicrobials, such as fluoroquinolones (FQs) and $\beta$-lactams, is a serious threat to human health [10]. FQ resistance was identified in $S$. aureus from food-producing animals [19], but not in Japan [20, 29]. In addition, transmission of methicillin-resistant $S$. aureus (MRSA) to humans through livestock products is a worldwide concern on public health $[1,2,11,27]$. Recently,

*Correspondence to: Asai, T., National Veterinary Assay Laboratory, 1-15-1 Tokura, Kokubunji, Tokyo 185-8511, Japan. e-mail: asai-t@nval.maff.go.jp

C2012 The Japanese Society of Veterinary Science
MRSA ST398 of food animal origin was reported in several European countries, while in Japan, MRSA was found in cattle [11] and swine [2].

The objective of this study was to determine the prevalence of antimicrobial resistance in $S$. aureus from diseased food-producing animals in Japan. Furthermore, we analyzed the characteristics of $S$. aureus isolates resistant to methicillin and FQ.

\section{MATERIALS AND METHODS}

Bacteria: A total of 290 S. aureus isolates from a variety of clinical specimens of cattle $(n=246)$, swine $(n=16)$, and chickens $(n=28)$ were provided by the Livestock Hygiene Service Centers of 23 prefectures throughout Japan between 2003 and 2009 (Table 1). Of the 246 bovine isolates, 236 were isolated from clinical or subclinical mastitis milk of dairy cows. Of the 16 porcine isolates, 7 isolates were derived from dermatitis, one from arthritis, and the remaining from unknown sites. Twenty-eight avian isolates were isolated from the liver, meat, and spleen of diseased birds with growth insufficiency, debility, diarrhea, decreased egg-laying rate, and unknown death. The isolates were preserved in $10 \%$ skimmed milk at $-80^{\circ} \mathrm{C}$ until use.

Antimicrobial susceptibility testing: All the isolates were tested for susceptibility to penicillin G (PC), oxa- 
Table 1. Staphylococcus aureus isolated from food-producing animals in Japan between 2003 and 2009

\begin{tabular}{llccrrrrrr}
\hline Origin & & 2003 & 2004 & 2005 & 2006 & 2007 & 2008 & 2009 & Total \\
\hline Cattle & Mastitis & 28 & 16 & 19 & 16 & 33 & 42 & 82 & 236 \\
& Others & & & 1 & 1 & 2 & 3 & 3 & 10 \\
\multirow{5}{*}{ Swine } & Dermatitis & & & 1 & & & 3 & 3 & 7 \\
& Arthritis & & & & 1 & & & & 1 \\
& Unknown & 3 & & 1 & & 3 & & 1 & 8 \\
Chicken & & 2 & 4 & 7 & & 9 & 3 & 3 & 28 \\
\hline & & 33 & 20 & 29 & 18 & 47 & 51 & 92 & 290 \\
\hline
\end{tabular}

cillin (MPIPC), cefazolin (CEZ), oxytetracycline (OTC), erythromycin (EM), dihydrostreptomycin (DSM), kanamycin (KM), gentamicin (GM), and enrofloxacin (ERFX) using an agar dilution method of the Clinical Laboratory Standards Institute [4]. S. aureus ATCC 29213, Enterococcus faecalis ATCC29212, Escherichia coli ATCC 25922 and Pseudomonas aeruginosa ATCC 27853 were used as quality control strains. The minimum inhibitory concentrations (MICs) of each antimicrobial were interpreted using the CLSI criteria [5]. The resistant breakpoints of DSM, OTC, and ERFX were defined microbiologically when the MIC distribution of antimicrobials was bimodal.

Molecular characterization of MRSA and FQ-resistant isolates: For the identification of MRSA, the presence of the $m e c A$ gene was shown for an MPIPC-resistant isolate followed using a published method [14]. Multi-locus sequence typing (MLST) was conducted for the MRSA isolate: seven housekeeping genes identified in a study [6] were amplified by PCR, and the sequence typing of the isolate was determined using the MLST website (www.mlst.net). The SCCmec type was classified according to a previous study [17]. The spa type was identified according to the method previously published [25]. Detection of the Panton-Valentine leucocidin (PVL) gene and the $\operatorname{arcA}$ gene encoded by the arginine catabolic mobile element (ACME) was performed as previously described $[13,30]$.

ERFX-resistant $S$. aureus isolates were examined for mutations of the quinolone-resistance determining regions (QRDR) of gyrA and parC by PCR [24] and DNA sequencing of the PCR products. Genomic information of the $S$. aureus ATCC 12600 strain and COL strain [9] were utilized for $g y r A$ and for parC as wild type strains, respectively.

Statistical analysis: The results of the antimicrobial susceptibility were statistically compared between each animal species using the chi-square test. For each comparison, a $P$ value of $<0.05$ was considered to be a significant difference. When at least one expected frequency was less than five, Fisher's exact-test was used for comparison between two groups.

\section{RESULTS}

Overall, resistance to $\mathrm{PC}$ was most frequently found $(24.8 \%)$, followed by OTC $(10.0 \%)$, DSM (4.1\%), EM (3.1\%), ERFX (2.1\%), and KM (1.7\%) as shown in Table 2. Only one bovine isolate was resistant to MPIPC and CEZ. Regarding animal species, PC resistance was found in
$22.0 \%(54 / 246)$ of the bovine isolates, $93.8 \%(15 / 16)$ of the porcine isolates, and $10.7 \%(3 / 28)$ of the chicken isolates. The PC resistance rate was significantly higher in swine than in cattle $(P<0.01)$ and chickens $(P<0.01)$. The OTC resistance rate was significantly higher in swine $(50.0 \%, 8 / 16$; $P<0.01)$ and chickens $(67.9 \%, 19 / 28 ; P<0.01)$ than in cattle $(0.8 \%, 2 / 246)$. The EM resistance was frequently found in isolates from swine $(18.8 \%, 3 / 16 ; P<0.01)$ and chickens $(10.7 \%, 3 / 28 ; P<0.05)$, compared with cattle $(1.2 \%, 3 / 246)$. The ERFX resistance rate was significantly higher in swine $(12.5 \%, P<0.01)$ and chickens $(10.7 \%, P<0.05)$ than in cattle $(0.4 \%)$.

Antimicrobial resistance patterns are shown in Table 3. Multidrug resistance (resistance to two or more classes of antimicrobials) was observed in $68.8 \%(11 / 16)$ of the porcine isolates in this study. The percentage of multidrugresistant isolates was greater in swine isolates than bovine isolates (4.5\%) and chicken isolates (25.0\%).

Of the PC-resistant isolates, one of dairy cow origin was resistant to MPIPC and CEZ, and harbored mecA. The sequence type (ST) of the MRSA isolate was 8 (3-3-1-1-4-4-3) as determined by MLST. The subtype of SCCmec IV for this MRSA isolate was neither a, b, c nor d and the spa type was classified as t024 (11-12-21-17-34-24-34-22-25). The MRSA isolate was negative for the PVL and $\operatorname{arc} A$ genes.

There were six ERFX-resistant isolates; one from cattle, two from swine and three from chickens (Table 4). The MIC of ERFX was $4 \mu \mathrm{g} / \mathrm{m} l$ in all the resistant isolates. One of the ERFX-resistant isolates was MRSA. Amongst ERFX-resistant isolates, the bovine isolate had mutations of Ser84Leu and Ser80Tyr in GyrA and ParC, respectively. The three avian isolates and a porcine isolate from 2007 had mutations of Ser84Leu and Ser80Phe in GyrA and ParC, respectively. The remaining porcine isolate had only a mutation of Ser80Phe in ParC.

\section{DISCUSSION}

The present study showed that most of bovine isolates exhibited susceptibility to the antimicrobials tested, whereas antimicrobial resistance, including multidrug resistance, was frequently found in porcine and chicken isolates. Similar results were obtained in several species of intestinal bacteria of animal origins, for example enterococci $[15,16]$ and E. coli [15]. In Japan, antimicrobial use is largest in swine farming among the domestic animal industry, followed by broiler chickens [10]. Metaphylaxis is a common 
Table 2. Antimicrobial susceptibilities of Staphylococcus aureus isolates from food-producing animals in Japan between 2003 and 2009

\begin{tabular}{|c|c|c|c|c|c|c|c|c|c|c|c|c|}
\hline \multirow{3}{*}{$\begin{array}{l}\begin{array}{c}\text { Antimicrobial } \\
\text { agent }^{\text {a) }}\end{array} \\
\text { PC }\end{array}$} & \multirow{3}{*}{$\begin{array}{c}\begin{array}{c}\text { Break } \\
\text { Point } \\
(\mu \mathrm{g} / \mathrm{m} l)\end{array} \\
0.25\end{array}$} & \multirow{3}{*}{$\begin{array}{l}\mathrm{MIC}^{\mathrm{b})} \text { range } \\
\quad(\mu \mathrm{g} / \mathrm{m} l) \\
\leq 0.125-256\end{array}$} & \multirow{3}{*}{$\begin{array}{l}\mathrm{MIC}_{50} \\
(\mu \mathrm{g} / \mathrm{m} l)\end{array}$} & \multirow{3}{*}{$\begin{array}{c}\mathrm{MIC}_{90} \\
(\mu \mathrm{g} / \mathrm{m} l)\end{array}$} & \multicolumn{8}{|c|}{ No. of resistant isolates (\%) } \\
\hline & & & & & \multicolumn{2}{|r|}{$\begin{array}{l}\text { Cattle }^{c)} \\
(\mathrm{n}=246)\end{array}$} & \multicolumn{2}{|c|}{$\begin{array}{l}\text { Swine } \\
(\mathrm{n}=16)\end{array}$} & \multicolumn{2}{|c|}{$\begin{array}{c}\text { Chicken } \\
(n=28)\end{array}$} & \multicolumn{2}{|c|}{$\begin{array}{c}\text { Total } \\
(\mathrm{n}=290)\end{array}$} \\
\hline & & & & & 54 & $(22.0)^{\mathrm{d})}$ & 15 & $(93.8)^{\mathrm{d}), \mathrm{e}}$ & 3 & $(10.7)^{\mathrm{e})}$ & 72 & $(24.8)$ \\
\hline MPIPC & 4 & $\leq 0.125-64$ & 0.25 & 0.5 & 1 & $(0.4)$ & 0 & & 0 & & 1 & $(0.3)$ \\
\hline CEZ & 32 & $\leq 0.125-128$ & 0.5 & 0.5 & 1 & $(0.4)$ & 0 & & 0 & & 1 & $(0.3)$ \\
\hline OTC & 16 & $\leq 0.125-256$ & 0.25 & 8 & 2 & $(0.8)^{\mathrm{f}), \mathrm{g})}$ & 8 & $(50.0)^{\mathrm{f})}$ & 19 & $(67.9)^{\mathrm{g})}$ & 29 & $(10.0)$ \\
\hline DSM & 32 & $0.5-512<$ & 4 & 8 & 10 & $(4.1)$ & 2 & $(12.5)$ & 0 & & 12 & $(4.1)$ \\
\hline $\mathrm{KM}$ & 64 & $\leq 0.125-512$ & 2 & 2 & 3 & $(1.2)$ & 1 & $(6.3)$ & 1 & (3.6) & 5 & (1.7) \\
\hline GM & 16 & $\leq 0.0315-32$ & 0.25 & 0.5 & 2 & $(0.8)$ & 1 & $(6.3)$ & 1 & $(3.6)$ & 4 & (1.4) \\
\hline EM & 8 & $\leq 0.125-512<$ & 0.25 & 0.5 & 3 & $(1.2)^{\mathrm{h}), \mathrm{i})}$ & 3 & $(18.8)^{\mathrm{h})}$ & 3 & $(10.7)^{i}$ & 9 & (3.1) \\
\hline ERFX & 4 & $\leq 0.063-4$ & $\leq 0.125$ & 0.25 & 1 & $(0.4)^{\mathrm{j}), \mathrm{k})}$ & 2 & $(12.5)^{\mathrm{j})}$ & 3 & $(10.7)^{\mathrm{k})}$ & 6 & (2.1) \\
\hline
\end{tabular}

a) Penicillin G, PC; oxacillin, MPIPC; cefazolin, CEZ; oxytetracycline, OTC; erythromycin, EM; dihydrostreptomycin, DSM; kanamycin, KM; gentamicin, GM; enrofloxacin, ERFX.

b) MIC: Minimum inhibitory concentration.

c) Origins of strains.

d), e), f), g), h) and j), the significant difference $(P<0.01)$ was observed, respectively. i) and $\mathrm{k})$, the significant difference $(P<0.05)$ was observed, respectively.

Table 3. Resistance pattern of Staphylococcus aureus isolates from food-producing animals in Japan between 2003 and 2009

\begin{tabular}{|c|c|c|c|c|c|}
\hline \multirow{2}{*}{ No. of antimicrobial } & \multirow{2}{*}{ Antimicrobial resistance pattern ${ }^{\text {a) }}$} & \multicolumn{4}{|c|}{ Origin } \\
\hline & & Cattle & Swine & Chicken & Total \\
\hline 0 & Susceptible & 186 & 1 & 6 & 193 \\
\hline \multirow[t]{5}{*}{1} & $\mathrm{PC}$ & 44 & 4 & 1 & 49 \\
\hline & DSM & 3 & & & 3 \\
\hline & OTC & 1 & & 13 & 14 \\
\hline & EM & 1 & & & 1 \\
\hline & ERFX & & & 1 & 1 \\
\hline \multirow[t]{8}{*}{2} & PC-DSM & 6 & & & 6 \\
\hline & PC-GM & 1 & & & 1 \\
\hline & KM-GM & 1 & & & 1 \\
\hline & PC-OTC & & 3 & 1 & 4 \\
\hline & PC-EM & 1 & 2 & & 3 \\
\hline & PC-ERFX & & 1 & & 1 \\
\hline & ERFX-OTC & & & 2 & 2 \\
\hline & EM-OTC & & & 3 & 3 \\
\hline \multirow[t]{4}{*}{3} & PC-EM-OTC & & 1 & & 1 \\
\hline & PC-GM-KM & & & 1 & 1 \\
\hline & PC-DSM-OTC & & 2 & & 2 \\
\hline & PC-ERFX-OTC & & 1 & & 1 \\
\hline \multirow[t]{2}{*}{4} & PC-DSM-KM-OTC & 1 & & & 1 \\
\hline & PC-GM-KM-OTC & & 1 & & 1 \\
\hline 5 & PC-CEZ-MPIPC-KM-EM-ERFX & 1 & & & 1 \\
\hline Total & & $246(11)^{b)}$ & $16(11)$ & $28(7)$ & $290(29)$ \\
\hline
\end{tabular}

practice in these animal species to control bacterial disease. In this study, the levels of PC resistance were highest among the antimicrobials tested in bovine $(22.0 \%)$ and porcine isolates (93.8\%). PC and ampicillin or a PC combination drug with DSM is widely chosen for treatments of porcine dermatitis and bovine mastitis in Japan. A previous study showed that $13(31.7 \%)$ of $41 \mathrm{~S}$. aureus isolates from bovine mastitis exhibited resistance to PC (MIC: higher than 0.78 Units $/ \mathrm{m} l$, equivalent to $0.47 \mu \mathrm{g} / \mathrm{m} l$ ) in 1997 and 1998 [29]. High resistance rates of staphylococci to PC were previously reported in porcine isolates (58.3\%) [20] and pork isolates (more than 60\%) [8] as well as this study. Almost half of the porcine isolates were resistant to OTC in this study. Tetracycline antibiotics are the most commonly used 
Table 4. Origin of animals, isolation site, minimum inhibitory concentration (MIC) value, and amino acid substitution at GyrA and ParC in enrofloxacin-resistant strains

\begin{tabular}{|c|c|c|c|c|c|c|c|}
\hline \multirow{2}{*}{$\begin{array}{l}\text { Isolation } \\
\text { Year }\end{array}$} & \multirow{2}{*}{$\begin{array}{l}\text { Origin of } \\
\text { Animal }\end{array}$} & \multirow{2}{*}{$\begin{array}{l}\text { Isolation } \\
\text { site }\end{array}$} & \multirow{2}{*}{ Strain } & \multirow{2}{*}{$\begin{array}{l}\text { MIC of ERFX } \\
\quad(\mu \mathrm{g} / \mathrm{m} l)\end{array}$} & \multicolumn{2}{|c|}{ Amino acid substitution in } & \multirow{2}{*}{ Resistance pattern $^{\text {a) }}$} \\
\hline & & & & & GyrA & ParC & \\
\hline 2003 & Dairy cow & Milk & $15-10$ & 4 & S84L & S80Y & PC-MPIPC-CEZ-KM-EM-ERFX \\
\hline 2005 & Chicken & Liver & $17-33$ & 4 & S84L & $\mathrm{S} 80 \mathrm{~F}$ & OTC-ERFX \\
\hline \multirow[t]{3}{*}{2007} & Chicken & Liver & $19-11$ & 4 & S84L & S80F & OTC-ERFX \\
\hline & & & $19-32$ & 4 & S84L & $\mathrm{S} 80 \mathrm{~F}$ & ERFX \\
\hline & Swine & Tonsil & $19-27$ & 4 & $\mathrm{~S} 84 \mathrm{~L}$ & $\mathrm{~S} 80 \mathrm{~F}$ & PC-OTC-ERFX \\
\hline 2009 & Swine & Skin & $21-1$ & 4 & $\mathrm{WT}^{\mathrm{b})}$ & S80F & PC-ERFX \\
\hline
\end{tabular}

a) Penicillin G, PC; oxacillin, MPIPC; cefazolin, CEZ; oxytetracycline, OTC; erythromycin, EM; kanamycin, KM.

b) WT: wild type.

antimicrobials in the Japanese veterinary field, especially the pig industry [10]. On the other hand, the rate of OTC resistance among bovine isolates remains low in this study. In bovine $S$. aureus isolates in the late of 1990s in Japan, OTC resistance (MIC: more than $25 \mu \mathrm{g} / \mathrm{m} l$ ) was observed in 2 isolates $(4.8 \%)$ [29].

The high virulent MRSA clone (USA 300 clone; ST8IVa with PVL and ACME) were spread among humans in communities and patients in hospitals in the United States $[21,28]$. This MRSA clone was also identified in some Japanese humans in 2008 [12]. However, the MRSA isolate (ST8-IV/t024) from dairy cow in this study did not harbor the PVL gene and ACME. As for food-producing animals in Japan, MRSA ST5-II/t002, ST5-II/t375 and ST509-IIIa/ t5266 from mastitis milk of cattle and ST221-untypable (type $1 \mathrm{ccr}$ and unidentified mec complex class)/t002 from the nasal swab of a slaughtered pig were reported $[2,11]$. In Japan, MRSA ST8-IV (SCCmec subtype was not a, b and c; spa type was not determined) strains, which were negative for the PVL gene, had already emerged in outpatients in the early 2000s [22]. Thus, the MRSA isolate from a dairy cow may be derived from human MRSA carriers in the community.

The appearance of FQ resistance was found in bovine $S$. aureus isolates after 2003 and porcine and avian $S$. aureus isolates after 2007. Although FQ resistance was reported in $S$. epidermidis from a pig [20], there are no FQ-resistant $S$. aureus obtained from food-producing animals in 2000 [20, 29]. Most of the ERFX-resistant isolates were multidrugresistant in this study. For Gram-positive bacteria including S. aureus, amino acid substitution at QRDR in ParC and GyrA is responsible for quinolone resistance [7, 19]. In this study, although five ERFX-resistant isolates had amino acid substitutions in QRDR of both GyrA and ParC, one ERFX-resistant isolate from swine only had an amino acid substitution in QRDR of ParC (Table 4). These six isolates showed identical MICs for ERFX $(4 \mu \mathrm{g} / \mathrm{m} l)$. Thus, activation of efflux may be associated with ERFX resistance in the porcine isolate having only an amino acid substitution in QRDR of ParC, as suggested in a previous study [18].

Finally, the antimicrobial susceptibility of $S$. aureus isolates from food-producing animals obtained over 7 years was examined. Neither an increase nor decrease of antimicrobial resistance was observed over this study period.
However, the emergence and prevalence of MRSA and FQ-resistant $S$. aureus in the animals should be noticed. It will be necessary to conduct continuous monitoring and epidemiological studies in food-producing animals to protect public health in Japan.

ACKNOWLEDGMENTS. We deeply appreciate the veterinary professionals of the Japanese Livestock Hygiene Service Centers for providing isolates of $S$. aureus. This work was supported in part by a grant-in aid from the Japanese Ministry of Health, Labour and Welfare (H21-ShokuhinIppan-013).

\section{REFERENCES}

1. Aspiroz, C., Lozano, C., Vindel, A., Lasarte, J. J., Zarazaga, M. and Torres, C. 2010. Skin lesion caused by ST398 and ST1 MRSA, Spain. Emerg. Infect. Dis. 16: 157-159. [Medline] [CrossRef]

2. Baba, K., Ishihara, K., Ozawa, M., Tamura, Y. and Asai, T. 2010. Isolation of meticillin-resistant Staphylococcus aureus (MRSA) from swine in Japan. Int. J. Antimicrob. Agents 36: 352-354. [Medline] [CrossRef]

3. Barkema, H. W., Schukken, Y. H. and Zadoks, R. N. 2006. Invited Review: The role of cow, pathogen, and treatment regimen in the therapeutic success of bovine Staphylococcus aureus mastitis. J. Dairy Sci. 89: 1877-1895. [Medline] [CrossRef]

4. Clinical and Laboratory Standards Institute 2008. Performance standards for antimicrobial disk and dilution susceptibility tests for bacteria isolated from animals, 3rd edition. Approved standard M31-A3. Wayne, PA.

5. Clinical and Laboratory Standards Institute 2008. Performance standards for antimicrobial susceptibility testing; eighteenth informational supplement. CLSI document M100-S16. Wayne, PA.

6. Enright, M. C., Day, N. P., Davies, C. E., Peacock, S. J. and Spratt, B. G. 2000. Multilocus sequence typing for characterization of methicillin-resistant and methicillin-susceptible clones of Staphylococcus aureus. J. Clin. Microbiol. 38: 10081015. [Medline]

7. Ferrero, L., Cameron, B. and Crouzet, J. 1995. Analysis of gyrA and grlA mutations in stepwise-selected ciprofloxacinresistant mutants of Staphylococcus aureus. Antimicrob. Agents Chemother. 39: 1554-1558. [Medline]

8. Fujio, K., Shimizu, A., Matsumura, K., Kawano, J., Kitagawa, H. and Igimi, S. 2007. Antimicrobial resistance of Staphylococcus aureus isolates from commercial raw meat, humans, 
pigs and chickens. Jpn. J. Food Microbiol. 24: 100-106.

9. Gill, S. R., Fouts, D. E., Archer, G. L., Mongodin, E. F., Deboy, R. T., Ravel, J., Paulsen, I. T., Kolonay, J. F., Brinkac, L., Beanan, M., Dodson, R. J., Daugherty, S. C., Madupu, R., Angiuoli, S. V., Durkin, A. S., Haft, D. H., Vamathevan, J., Khouri, H., Utterback, T., Lee, C., Dimitrov, G., Jiang, L., Qin, H., Weidman, J., Tran, K., Kang, K., Hance, I. R., Nelson, K. E. and Fraser, C. M. 2005. Insights on evolution of virulence and resistance from the complete genome analysis of an early methicillin-resistant Staphylococcus aureus strain and a biofilm-producing methicillin-resistant Staphylococcus epidermidis strain. J. Bacteriol. 187: 2426-2438. [Medline] [CrossRef]

10. Harada, K. and Asai, T. 2010. Role of antimicrobial selective pressure and secondary factors on antimicrobial resistance prevalence in Escherichia coli from food-producing animals in Japan. J. Biomed. Biotechnol. 2010: 180682. [Medline] [CrossRef]

11. Hata, E., Katsuda, K., Kobayashi, H., Uchida, I., Tanaka, K. and Eguchi, M. 2010. Genetic variation among Staphylococcus aureus strains from bovine milk and their relevance to methicillin-resistant isolates from humans. J. Clin. Microbiol. 48: 2130-2139. [Medline] [CrossRef]

12. Higuchi, W., Mimura, S., Kurosawa, Y., Takano, T., Iwao, Y., Yabe, S., Razvina, O., Nishiyama, A., Ikeda-Dantsuji, Y., Sakai, F., Hanaki, H. and Yamamoto, T. 2010. Emergence of the community-acquired methicillin-resistant Staphylococcus aureus USA300 clone in a Japanese child, demonstrating multiple divergent strains in Japan. J. Infect. Chemother. 16: 292-297. [Medline] [CrossRef]

13. Ishihara, K., Shimokubo, N., Sakagami, A., Ueno, H., Muramatsu, Y., Kadosawa, T., Yanagisawa, C., Hanaki, H., Nakajima, C., Suzuki, Y. and Tamura, Y. 2010. Occurrence and molecular characteristics of methicillin-resistant Staphylococcus aureus and methicillin-resistant Staphylococcus pseudintermedius in an academic veterinary hospital. Appl. Environ. Microbiol. 76: 5165-5174. [Medline] [CrossRef]

14. Kawano, J., Shimizu, A., Saitoh, Y., Yagi, M., Saito, T. and Okamoto, R. 1996. Isolation of methicillin-resistant coagulase-negative staphylococci from chickens. J. Clin. Microbiol. 34: 2072-2077. [Medline]

15. Kojima, A., Asai, T., Ishihara, K., Morioka, A., Akimoto, K., Sugimoto, Y., Sato, T., Tamura, Y. and Takahashi, T. 2009. National monitoring for antimicrobial resistance among indicator bacteria isolated from food-producing animals in Japan. J. Vet. Med. Sci. 71: 1301-1308. [Medline] [CrossRef]

16. Kojima, A., Morioka, A., Kijima, M., Ishihara, K., Asai, T., Fujisawa, T., Tamura, Y. and Takahashi, T. 2010. Classification and antimicrobial susceptibilities of enterococcus species isolated from apparently healthy food-producing animals in Japan. Zoonoses Public Health 57: 137-141. [Medline] [CrossRef]

17. Kondo, Y., Ito, T., Ma, X. X., Watanabe, S., Kreiswirth, B. N., Etienne, J. and Hiramatsu, K. 2007. Combination of multiplex PCRs for staphylococcal cassette chromosome mec type assignment: rapid identification system for mec, ccr, and major differences in junkyard regions. Antimicrob. Agents Chemother. 51: 264-274. [Medline] [CrossRef]

18. Li, X. Z. and Nikaido, H. 2009. Efflux-mediated drug resistance in bacteria: an update. Drugs 69: 1555-1623. [Medline] [CrossRef]
19. Lin, A. E. and Davies, J. E. 2007. Occurrence of highly fluoroquinolone-resistant and methicillin-resistant Staphylococcus aureus in domestic animals. Can. J. Microbiol. 53: 925-929. [Medline] [CrossRef]

20. Morioka, A., Asai, T., Ishihara, K., Kojima, A., Tamura, Y. and Takahashi, T. 2005. In vitro activity of 24 antimicrobial agents against Staphylococcus and Streptococcus isolated from diseased animals in Japan. J. Vet. Med. Sci. 67: 207-210. [Medline] [CrossRef]

21. Otter, J. A., Havill, N. L., Boyce, J. M. and French, G. L. 2009. Comparison of community-associated methicillin-resistant Staphylococcus aureus from teaching hospitals in London and the USA, 2004-2006: where is USA300 in the UK? Eur. J. Clin. Microbiol. Infect. Dis. 28: 835-839. [Medline] [CrossRef]

22. Piao, C., Karasawa, T., Totsuka, K., Uchiyama, T. and Kikuchi, K. 2005. Prospective surveillance of community-onset and healthcare-associated methicillin-resistant Staphylococcus aureus isolated from a university-affiliated hospital in Japan. Microbiol. Immunol. 49: 959-970. [Medline]

23. Saif, T.M., Barnes, H.J., Glisson, J.R., Fandly, A.M., McDouglad, L.R. and Swayne, D.E. 2003. Disease of poultry.

24. Schmitz, F. J., Hofmann, B., Hansen, B., Scheuring, S., Luckefahr, M., Klootwijk, M., Verhoef, J., Fluit, A., Heinz, H. P., Kohrer, K. and Jones, M. E. 1998. Relationship between ciprofloxacin, ofloxacin, levofloxacin, sparfloxacin and moxifloxacin (BAY 12-8039) MICs and mutations in grlA, grlB, gyrA and gyrB in 116 unrelated clinical isolates of Staphylococcus aureus. J. Antimicrob. Chemother. 41: 481-484. [Medline] [CrossRef]

25. Shopsin, B., Gomez, M., Montgomery, S. O., Smith, D. H., Waddington, M., Dodge, D. E., Bost, D. A., Riehman, M., Naidich, S. and Kreiswirth, B. N. 1999. Evaluation of protein A gene polymorphic region DNA sequencing for typing of Staphylococcus aureus strains. J. Clin. Microbiol. 37: 35563563. [Medline]

26. Straw, B. E., Zimmerman, J. J., D’Allaire, S. and Taylor, D. J. 2006. Diseases of Swine, 9th Edition.

27. Sung, J. M., Lloyd, D. H. and Lindsay, J. A. 2008. Staphylococcus aureus host specificity: comparative genomics of human versus animal isolates by multi-strain microarray. Microbiology 154: 1949-1959. [Medline] [CrossRef]

28. Yamamoto, T., Nishiyama, A., Takano, T., Yabe, S., Higuchi, W., Razvina, O. and Shi, D. 2010. Community-acquired methicillin-resistant Staphylococcus aureus: community transmission, pathogenesis, and drug resistance. J. Infect. Chemother. 16: 225-254. [Medline] [CrossRef]

29. Yoshimura, H., Ishimaru, M. and Kojima, A. 2002. Minimum inhibitory concentrations of 20 antimicrobial agents against Staphylococcus aureus isolated from bovine intramammary infections in Japan. J. Vet. Med. B Infect. Dis. Vet. Public Health 49: 457-460. [Medline] [CrossRef]

30. Zhang, K., McClure, J. A., Elsayed, S., Louie, T. and Conly, J. M. 2008. Novel multiplex PCR assay for simultaneous identification of community-associated methicillin-resistant Staphylococcus aureus strains USA300 and USA400 and detection of mecA and Panton-Valentine leukocidin genes, with discrimination of Staphylococcus aureus from coagulase-negative staphylococci. J. Clin. Microbiol. 46: 1118-1122. [Medline] [CrossRef] 